\title{
The familial incidence of intracranial aneurysms
}

\author{
VIJAY K. KAK ${ }^{1}$, COLIN A. GLEADHILL, AND IAN C. BAILEY \\ From the Department of Neurological Surgery, Royal Victoria Hospital, Belfast, Northern Ireland, and the \\ Department of Neurological Surgery, Mulago Hospital, Kampala, Uganda
}

The occurrence of familial cerebral aneurysms lends support to the importance of congenital factors in their pathogenesis. The information on the subject is, however, still meagre, there being less than 20 reports in literature. Earlier literature mentions the occurrence of cerebrovascular accidents in members of the same family with polycystic kidneys (Dunger, 1904). Tönnis and Lange-Cosack (1953) reported angiomas in several members of one family. O'Brien (1942) reported a case with a middle cerebral artery aneurysm whose twin brother might have died from an 'acute cerebrovascular episode' eight years previously. Sudden death in identical twins from such diseases was described by Jokl and Wolffe (1954), but at necropsy evidence was lacking in their report. In the same year, Chambers, Harper, and Simpson (1954) reported proven ruptured aneurysms in father and son, on the middle cerebral artery and the anterior communicating artery respectively. In Bruce's revision of Wilson's Neurology (Wilson, 1955), similar mention is made of evidence of their dysplastic origin is afforded by occasional appearance in more than one member of a family', without further details. Walton (1956) described six instances of familial subarachnoid haemorrhage, but no specific details were given. Ross (1959) described a woman with left parieto-occipital angioma and left middle cerebral artery aneurysm whose mother had died of a recurrent subarachnoid haemorrhage after ligation of the carotid artery for a posterior communicating artery aneurysm. Ullrich and Sugar (1960) reported similar disorders in a man with a middle cerebral artery aneurysm whose brother had died after surgery for an anterior communicating artery aneurysm, two brothers who had middle cerebral artery aneurysms on opposite sides of head, a man with multiple (four) aneurysms whose brother had died of a 'cerebial haemorrhage' (no necropsy) and the brother's son had also died after subarachnoid haemorrhage due to an aneurysm at the junction of the anterior cerebral and the anterior communicating arteries, and a brother-sister pair with internal carotid artery

1Present address: Postgraduate Institute of Medical Education and Research, Chandigarh, India. aneurysms on opposite sides of the head. McKusick (1961) mentioned a man and his daughter, both of whom had died of intracranial berry aneurysms; further details were not given. Without specific details, Stark (1962) described three sisters affected by the same malady. Phillips (1963) reported two sisters with identical posterior communicating artery aneurysms on the same side of the head rupturing in the same decade. In an addendum to Phillips's paper, Matson (1963) is cited as having described a patient with an internal carotid artery aneurysm whose father and sister had similar aneurysms. Sahs, Perret, Locksley, Nishioka, and Skultety (1966), in the Report of the Co-operative Study, referred to the published instances of familial aneurysms but the matter is not dealt with any further. Graf (1966) reported four cases of this incidence, a sister-brother pair with identical middle cerebral artery aneurysms on the same side, and two sisters with identical posterior communicating artery aneurysms, again on the same side of the head. Logue, Durward, Pratt, Piercy, and Nixon (1968), in a series of 90 patients with anterior cerebral artery aneurysms found two parents who had died of subarachnoid haemorrhage, but no necropsies had been done. Beumont (1968) reviewed cases from the English literature and added to these a family with three sisters affected, one with a parietal angioma and an internal carotid artery aneurysm, another with bilateral middle cerebral artery aneurysms, and the third with a posterior communicating aneurysm.

Published references in the foreign literature are equally sparse (Becker, 1966). Eck (1957) recorded a case with an anterior communicating artery aneurysm whose brother had died of a 'stroke' in his middle 40s, and two brothers whose necropsies had revealed aneurysms on the basilar artery and the junction of the anterior cerebral and the anterior communicating arteries respectively. Asenjo, Uiberall, and Fierro (1957) also refer to a case similar to that of Chambers et al. (1954) without specific details. Krayenbühl and Yasargil (1958) in their monograph described the case of a man with an arteriovenous malformation who had two brothers 
with anterior communicating artery aneurysms and a son with a 'saccular' aneurysm.

In a previous survey from this centre (Chakravorty and Gleadhill, 1966) six cases of familial cerebral aneurysms confirmed by arteriography were reported-a brother-sister pair and two mother-son pairs. These came from 337 cases during the period 1957 to 1965. A further 204 cases of proven intracranial aneurysms were admitted to this unit during the period 1965 to 1968 . Four more cases showed this familial incidence. It is the purpose of this communication to report these four additional cases.

\section{CASE REPORTS}

CASE 1 H.J.A., a 52-year-old man, was admitted on 2 July 1964 with a sudden onset of headache and vomiting, and transient numbness of the right leg. The only abnormal sign on examination was neck stiffness. Blood pressure was $190 / 100 \mathrm{~mm} \mathrm{Hg}$. The diagnosis of subarachnoid haemorrhage was confirmed by lumbar puncture. Four days after admission he suffered a second haemorrhage after which the level of consciousness deteriorated and he developed a right hemiplegia. A week after admission he had improved to the extent of obeying simple commands, and had slurred speech. There was right facial weakness, and weakness of the right arm and both the legs. On 10 July a left carotid arteriogram demonstrated an aneurysm at the junction of the left anterior cerebral and the anterior communicating arteries. The left anterior cerebral artery was in spasm. There was no evidence of a haematoma. His neurological deficit took a long time to recover, the weakness on the left side recovering first followed by improvement on the right side. The patient at this stage had profound confusion, memory loss, and difficulty in registering information. He was transferred back to the referring hospital on 17 September 1964.

He was readmitted on 25 January 1965 for reassessment, when his mental functions had recovered to a large extent. He had slight difficulty in registering information, residual spasticity of the right limbs, and increased tendon reflexes on that side. Blood pressure was $145 / 100 \mathrm{~mm} \mathrm{Hg}$. Left carotid arteriogram was repeated on 26 January. The aneurysm still showed good filling (Fig. 1), but this time there was a good cross circulation. Two days later the left anterior cerebral artery was clipped. Post-operatively he developed slight confusion, dysphasia, right facial weakness, and incontinence of urine. These cleared up in a week's time, and he was discharged on 11 February 1965. Four years later he has residual spasticity of the right leg and poor memory.

CASE 2 R.A., 58-year-old brother of case 1, suddenly developed headache on 25 December 1967 and lost consciousness. On admission to the hospital he was drowsy, having right-sided twitchings and had an equivocal left plantar response. He had neck stiffness. Blood pressure was $155 / 90 \mathrm{~mm} \mathrm{Hg}$. Lumbar puncture

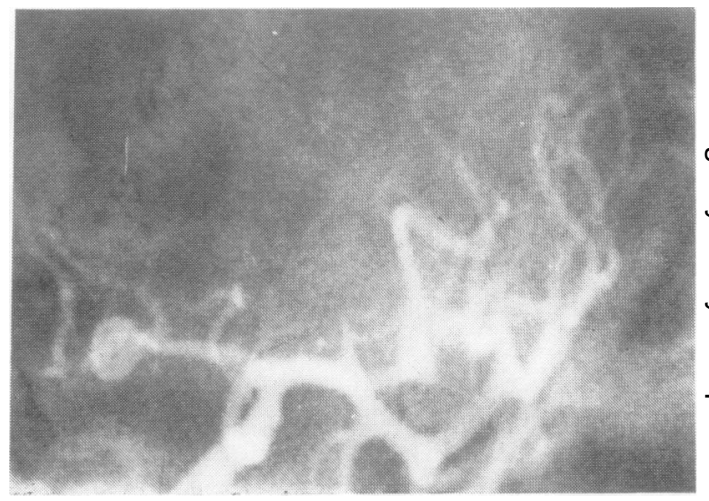

FIG. 1. Left carotid arteriogram of case 1, showing an aneurysm at the junction of the left anterior cerebral w and the anterior communicating artery.

confirmed subarachnoid haemorrhage. Bilateral carotid arteriography on 2 January 1968 revealed an aneurysm at the junction of the left anterior cerebral and the anterior communicating arteries (Fig. 2). There was good cross $\dot{\omega}$ circulation from the right to the left side. On 4 January a Mayfield clip was applied on the left anterior cerebrad artery. After operation he developed confusion, slurred speech, jargon dysphasia, and urinary incontinences. 을 He recovered from these signs within a week and wa discharged on 26 January. A year later he is back $\mathrm{gt}_{\mathrm{t}} 7$ full-time work.

COMMENT The family tree of these brothers is show in Figure 3. Both brothers bled from their aneurysus $-\overrightarrow{0}$ in the fifth decade of their lives. Their aneurysms we

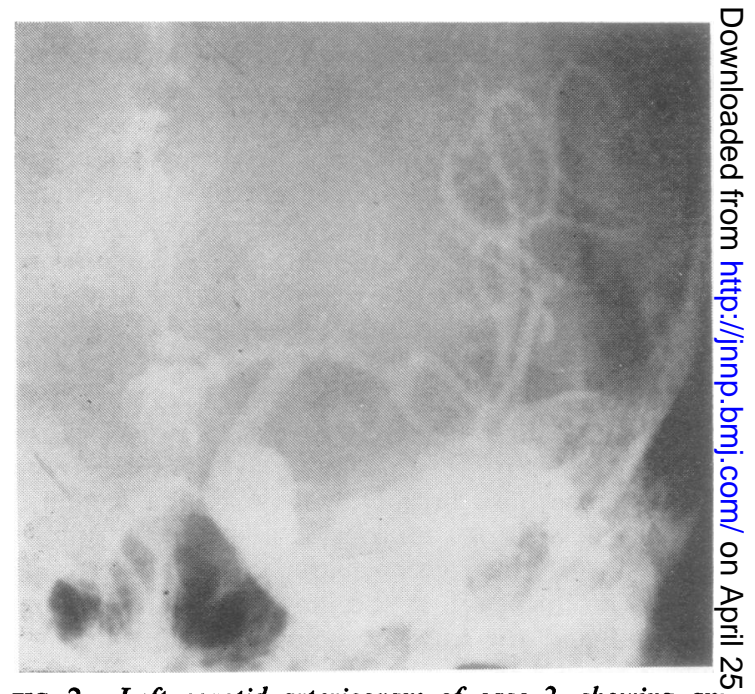

FIG. 2. Left carotid arteriogram of case 2, showing an aneurysm at the junction of the left anterior cerebral and the anterior communicating artery. 


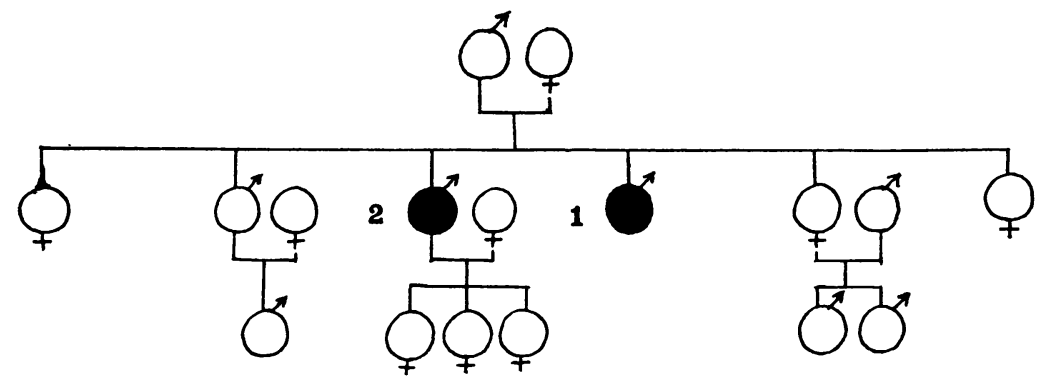

FIG. 3. The family tree of cases 1 and 2. Their parents died in old age of non-cerebral diseases. Remaining members of second and third generation are alive and well. located at virtually identical sites on the circle of Willis. After proximal clipping of the anterior cerebral artery each developed a transient state of confusion, speech difficulty and incontinence post-operatively. The blood group of both the cases was $\mathrm{O}$ - rhesus positive.

CASE 3 P.C., a 46-year-old man, was admitted on 3 August 1965 after a sudden onset of headache, pain in the neck and vomiting. Clinical examination revealed neck stiffness and positive Kernig's sign. There were no other neurological abnormalities. Blood pressure was $135 / 95 \mathrm{~mm} \mathrm{Hg}$. Cerebrospinal fluid obtained at lumbar puncture was uniformly blood stained. There was a history of the patient having received psychiatric treatment in the past for depression. Bilateral carotid arteriography done on 9 August demonstrated a bilocuiar aneurysm arising from the right internal carotid artery (Fig. 4). Three days later the right common carotid artery was ligated, a pressure drop of $36^{\circ} \%$ being obtained. The post-operative course was satisfactory, and he remains at full work without any neurological deficit $3 \frac{1}{2}$ years later.

CASE 4 T.E.C., a brother of case 3, at the age of 25 years had received treatment at the Neurosurgical Unit, Manchester Royal Infirmary, in 1950, having been admitted there after a subarachnoid haemorrhage. Clinical examination revealed no abnormal signs except neck stiffness. Arteriography showed an aneurysm arising from the bifurcation of the right internal carotid artery (Fig. 5). This was treated by right common carotid artery ligation. Eighteen years after operation he has no symptoms or signs and is working full time in the fishing industry.

COMMENT Figure 6 shows the family tree of these brothers. The younger brother had his episode of subarachnoid haemorrhage at the age of 25 years, the older at 46 years. Both had aneurysms arising from the same segment of the circle of Willis on the same side of the head. The blood group of case 3 was $\mathrm{O}-$ rhesus positive, that of case 4 is not known. Both are alive and well at the time of this report.

\section{DISCUSSION}

The incidence of the occurrence of familial cerebral aneurysms has not been widely reported in the literature. In a consecutive series of 276 patients (Krayenbühl and Yasargil, 1958) a sib was affected in two instances. Logue et al. (1968) in a review of 90 patients with anterior cerebral artery aneurysms found two parents who had died of subarachnoid haemorrhage, but necropsy evidence was lacking. In the same series there was no suggestive history in 360 sibs surviving beyond infancy. Chakravorty and Gleadhill (1966) from this centre reviewed 337 cases of proven intracranial aneurysms and found six cases showing this familial incidence. Pratt (1967) did not consider that these figures

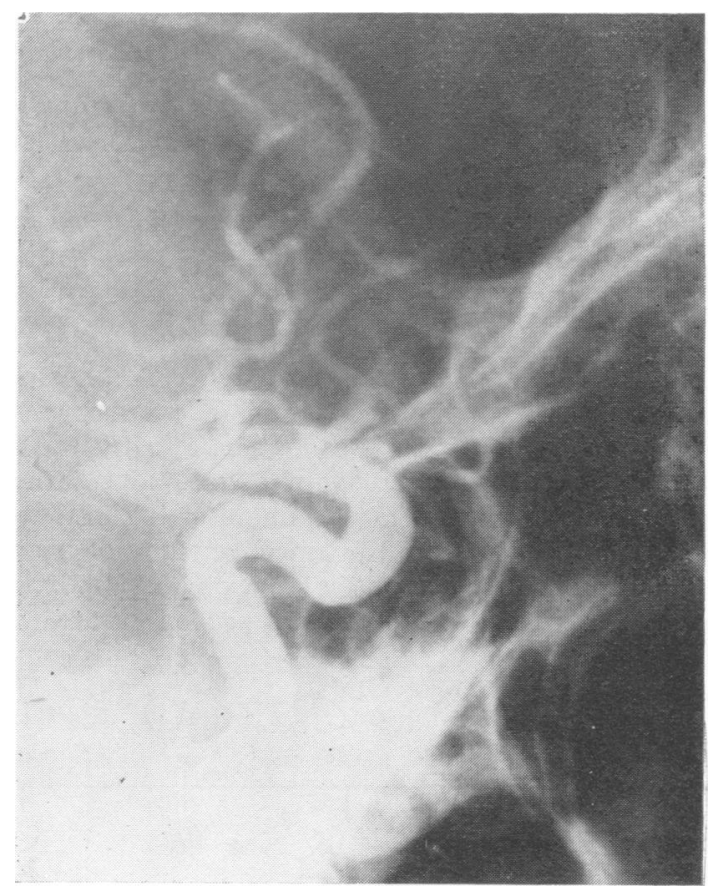

FIG. 4. Right carotid arteriogram of case 3, showing an aneurysm arising from the internal carotid artery at the level of the posterior communicating artery. 
TABLE 1

SUMMARY OF CASES SHOWING FAMILIAL INCIDENCE OF INTRACRANIAL ANEURYSMS ENCOUNTERED AT THE NEURO SURGICAL UNIT, ROYAL VICTORIA HOSPITAL, BELFAST OVER A 12 YEAR PERIOD (1957 TO 1968)

\begin{tabular}{|c|c|c|c|c|c|c|}
\hline Pair & Relationship & Case I & (Sex, age, site) & Case 2 & Sex, age, site) & $\bar{E}$ \\
\hline$* 1$ & Sibs & M 52 & $\begin{array}{l}\text { Right PCA } \\
\text { Right MCA } \\
\text { Left MCA }\end{array}$ & F 45 & Left MCA & \\
\hline *2 & Mother - son & F 62 & Right carotid syphon & M 34 & Left carotid bifurcation & 0 \\
\hline$* 3$ & Mother - son & F 42 & Left MCA & M 15 & A Com A & \\
\hline 4 & Brothers & M 52 & A Com A & M 58 & A Com A & \\
\hline 5 & Brothers & M 46 & Right PCA & M 25 & Right carotid bifurcation & \\
\hline
\end{tabular}

Key to abbreviations: $\mathbf{M}=$ Male, $\mathbf{F}=$ Female, $\mathbf{P C A}=$ Posterior communicating artery; $\mathbf{M C A}=\mathbf{M i d d l e}$ cerebral artery; $\mathbf{A}$ Com $\mathbf{A}=$ AnteriōO communicating artery.

*These cases were reported in an earlier publication (Chakravorty and Gleadhill, 1966).

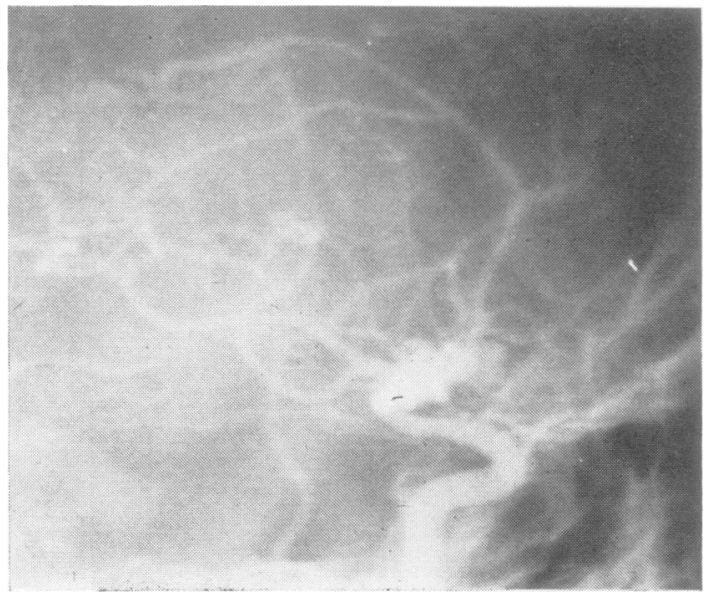

FIG. 5. Right carotid arteriogram of case 4, showing an aneurysm arising from the bifurcation of the internal carotid artery.

represented an increased risk to a relative, since the incidence of subarachnoid haemorrhage in the general population is as high as 6 to $16 / 100,000$ per year (Pakarinen, 1964; Crawford and Sarner, 1965), and an aneurysm was found in 137 instances (unruptured in 80 ) in a prospective study of nearly 2,800 consecutive necropsies (Chason and Hindman, 1958). In a total of 541 cases of proven intracranial aneurysms admitted to this unit over a 12 yearø period (1957 to 1968), 10 cases have shown thises familial incidence (Table 1). This figure does notinclude five more cases of proven intracraniat aneurysms, which have been excluded owing to $\vec{\omega}$ lack of well-documented evidence of an aneurysmo in their relatives who had died of a subarachnoid haemorrhage, but had no arteriography or necropsy? examination. This difficulty in correlating thec necropsy findings in members of a family, one of whom has had an aneurysm, emphasizes the fatc that these lesions might be commoner than hitherfoos reported. A prospective study of the families w $\vec{T}-$ a member having an intracranial aneurysm mighr $T_{\mathbb{D}}^{\top}$ reveal the true incidence of this familial treng. Before Beumont's report (1968) the only prospect approach had been that of Koch (1957) who reported ${ }^{2}$ a man dying of a ruptured cerebral aneurysm, whosec twin brother was alive and well 14 months later.

The origin of intracranial aneurysms has been a controversial subject. Fisher (1954) pointed out? that arteriosclerotic lesions of the larger vessels of the brain are common and have preferentialo loci. The incidence of aneurysms in these arterio-市 sclerotic patients is low. It is recognized that the basic defect in the causation of 'berry' aneurysmso of the circle of Willis is a maldevelopment of the embryonic vasculature resulting in a deficiency of the elastic layer at the bifurcation of a vessel(Forbus, 1930; Bremer, 1943; Padget, 1944). This 'congenital' hypothesis is further supported by the?

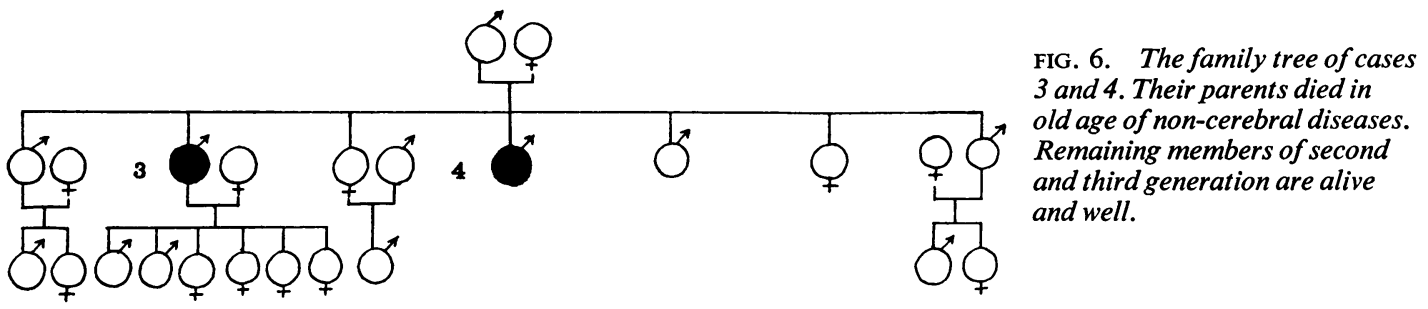

FIG. 6. The family tree of cases 3 and 4. Their parents died in old age of non-cerebral diseases. and third generation are alive and well. 
reports of the occurrence of cerebral aneurysms in children (Newcomb and Munns, 1949; Jones and Shearburn, 1961; Garcia-Chavez and Moossy, 1965) and the absence of the elastic layer in the wall of the aneurysm (Sugar, 1951).

The finding of these congenital lesions in more than one member of a family raises the questions concerning the role of genetic factors in their causation. Beumont (1968) suggested a pattern of simple dominant inheritance with subsequent events depending on variations in penetrance. Bilateral polycystic disease of the kidneys (adult form) is inherited as a dominant and is accompanied by the occurrence of intracranial aneurysms in $16 \%$ of gene carriers (Dalgaard, 1957). This association is responsible for an occasional familial concentration of intracranial aneurysms (Ditlefsen and Tönjum, 1960). Dominant transmission of the defect is also supported by the absence of consanguinity in the families described in this communication. The occurrence of aneurysms in two pairs of sibs at almost identical sites lends further support to the heredofamilial concept of origin of berry aneurysms of the circle of Willis and its branches.

It is nine years since Ullrich and Sugar (1960) expressed 'the hope that others will be encouraged to look for and report their cases of familial aneurysms'. We echo the same 'hope'.

\section{SUMMARY}

1. Two pairs of cases of cerebral aneurysms in brothers are reported, with their family trees. 2. Published instances in the literature are reviewed. 3. It is suggested that the actual incidence of the familial occurrence of intracranial aneurysms might be higher than so far reported in the literature.

We are indebted to Mr. R. T. Johnson, director of the Department of Neurosurgery, Manchester Royal Infirmary, for providing the case history and arteriogram of case 4. We are grateful to Mr. Hurt and the staff of the Department of Medical Photography, Royal Victoria Hospital, Belfast, for the illustrations.

\section{REFERENCES}

Asenjo, A., Uiberall, E., and Fierro, J. (1957). Afeceiones Vasculares Quirurgicas del Encephalo. Zig-Zag: Santiago de Chile.

Beumont, P. J. V. (1968). The familial occurrence of berry aneurysm. J. Neurol. Neurosurg. Psychiat., 31, 399-402.

becker, P. E. (1966). Humangenetik. Vol. 5, Part I: Krankheiten des Nervensystems. Thieme: Stuttgart.

Bremer, J. L. (1943). Congenital aneurysms of the cerebral arteries; embryologic study. Arch. Path., 35, 819-831.

Chakravorty, B. G., and Gleadhill, C. A. (1966). Familial incidence of cerebral aneurysms. Brit. med.J., 1, 147-148.

Chambers, W. R., Harper, B. F., Jr., and Simpson, J. R. (1954). Familial incidence of congenital aneurysms of cerebral arteries; report of cases of ruptured aneurysms in father and son. J. Amer. med. Ass., 155, 358-359.

Chason, J. L., and Hindman, W. M. (1958). Berry aneurysms of the circle of Willis; results of a planned autopsy study. Neuro$\operatorname{logy}$ (Minneap.), 8, 41-44.

Crawford, M. D., and Sarner, M. (1965). Ruptured intracranial aneurysms: community study. Lancet, 2, 1254-1257.

Dalgaard, O. Z. (1957). Bilateral Polycystic Disease of the Kidney. A Follow up of 284 Patients and their Families. Munksgaard: Copenhagen.

Ditlefsen, E. M. L., and Tönjum, A. M. (1960). Intracranial aneurysms and polycystic kidneys. Acta med. scand., 168, 51-54.

Dunger, R. (1904). Zur Lehre von der Cystenniere, mit besonderer Berücksichtigung ihrer Heredität. Beitr. path. Anat., 35, 445-509.

Eck, H. (1957). Uber die Erblichkeit von Hirnbasisaneurysmen. Münch. med. Wschr., 99, 1070-1071.

Fisher, M. (1954). Concerning cerebral arteriosclerosis. J. Amer. geriat. Soc., 2, 1-18.

Forbus, W. D. (1930). On the origin of miliary aneurysms of the superficial cerebral arteries. Bull. Johns Hopk. Hosp., 47, 239-284.

Garcia-Chuvez, C., and Moossy, J. (1965). Cerebral artery aneurysm in infancy: association with agenesis of the corpus callosum. J. Neuropath. exp. Neurol., 24, 492-501.

Graf, C. J. (1966). Familial intracranial aneurysms. J. Neurosurg. 25, 304-308.

Jokl, E., and Wolffe, J. B. (1954). Sudden non-traumatic death associated with physical exertion in identical twins. Acta Genet. med. (Roma), 3, 245-246.

Jones, R. K., and Shearburn, E. W. (1961). Intracranial aneurysm in a four-week-old infant. J. Neurosurg., 18, 122-124.

Koch, G. (1957). Ergebnisse aus der Nachuntersuchung der Berliner Zwillingsserie nach 20-25 Jahren (Vorläufige Ergebnisse) Acta genet. (Basel), 7, 47-52.

Krayenbühl, H., and Yasargil, M. G. (1958). Das Hirnaneurysma. Geigy: Basel.

Logue, V., Durward, M., Pratt, R. T. C., Piercy, M., and Nixon, W. L. B. (1968). The quality of survival after rupture of an anterior cerebral aneurysm. Brit. J. Psychiat., 114, 137-160.

Matson, D. D. (1963). Addendum to Phillips, R. L. (1963): Familial cerebral aneurysms. J. Neurosurg., 20, 701-703.

McKusick, V. A. (1961). Intracranial aneurysm. J. chron. Dis., 14, 146.

Newcomb, A. L., and Munns, G. F. (1949). Rupture of aneurysm of the circle of Willis in the newborn. Paediatrics, 3, 769-772.

O'Brien, J. G. (1942). Subarachnoid haemorrhage in identical twins. Brit. med. J., 1, 607-609.

Padget, D. H. (1944). The circle of Willis, its embryology and anatomy, pp. 67-90 in Intracranial Arterial Aneurysms. Edited by W. E. Dandy. Comstock: Ithaca, New York.

Pakarinen, S. (1964). Incidence and prognosis of subarachnoid haemorrhage in an urban population. Acta neurol. scand., 40, 190.

Phillips, R. L. (1963). Case reports and technical notes: familial cerebral aneurysms. J. Neurosurg., 20, 701-703.

Pratt, R. T. C. (1967). The Genetics of Neurological Disorders. Oxford University Press: London.

Ross, R. T. (1959). Multiple and familial intracranial vascular lesions. Canad. med. Ass. J., 81, 477-479.

Sahs, A. L., Perret, G., Locksley, H. B., Nishioka, H., and Skultety, F. M. (1966). Preliminary remarks on subarachnoid haemorrhage. J. Neurosurg., 24, 782-788.

Stark, D. C. C. (1962). Effects of giving vasopressors to patients on monoamine-oxidase inhibitors. Lancet, 1, 1405-1406.

Sugar, O. (1951). Pathological anatomy and angiography of intracranial vascular anomalies. J. Neurosurg., 8, 3-22.

Tönnis, W., and Lange-Cosack, H. (1953). Klinik, operative Behandlung und Prognose der arteriovenösen Angiome des Gehirns und seiner Häute. (Ein Bericht über 72 Fälle.) Dtsch. $Z$. Nervenheilk., 170, 460-485.

Ullrich, D. P., and Sugar, O. (1960). Familial cerebral aneurysms including one extracranial internal carotid aneurysm. Neurology (Minneap.), 10, 288-294.

Walton, J. N. (1956). Subarachnoid Haemorrhage. Livingstone: Edinburgh and London.

Wilson, S. A. K. (1955). In Neurology. 2nd Edn. Vol. 3. Edited by A. N. Bruce. Butterworth: London. 